\title{
Rising inequality and stagnation in the US economy
}

\author{
Barry Z. Cynamon* \\ Visiting Scholar, Federal Reserve Bank of St. Louis Center for Household Financial Stability, MO, USA
}

\author{
Steven M. Fazzari* \\ Departments of Economics and Sociology, Washington University in St. Louis, MO, USA
}

US household demand is well below its trend from prior to the Great Recession. We link weak demand to rising income inequality. The demand problem did not arise contemporaneously with higher income inequality because the bottom 95 percent of the income distribution went deeply into debt to maintain consumption growth despite their stagnant income growth. But we argue that the demand impact of greater inequality did appear in the aftermath of the recession. A calibrated Keynesian growth model shows that the lower income share of the bottom 95 percent can explain the deviation of the US economy from its pre-recession trend.

Keywords: aggregate demand, consumption, saving, household, national income and product accounts

JEL codes: D31, E01, E12, E21

\section{INTRODUCTION}

Economic inequality has risen substantially in many developed economies. In the US, the primary focus of this article, top income shares began to rise around 1980 after several decades of stability. This trend impacts the future of mature capitalism across multiple dimensions. Perhaps the most obvious of these, and likely the most politically potent, is social justice in an economy that increasingly operates to serve the interests and desires of the affluent. Other concerns include social costs imposed by rising tensions among citizens as the economic differences between them expand.

This paper focuses on a different dimension of rising inequality: its effects on demand generation. Economic models, going back at least to Kalecki (see Hein 2014: ch. 5 for a survey and extensive references), have explored the demand drag caused when a greater share of aggregate income accrues to groups that spend a smaller proportion of their income. However, empirical evidence that this phenomenon has actually affected modern economies with rising inequality is rather thin. In our recent research (Cynamon/Fazzari 2015a), we explore this issue in the US context. We conclude that rising inequality did indeed play a central role in the financial dynamics of the household sector that led up to the Great Recession. We also argue that historically elevated income inequality helps

* The authors thank the Institute for New Economic Thinking for generous financial support that made the research reported in this article possible. We are grateful to Till van Treeck for helpful comments. The analysis and conclusions set forth are those of the authors and do not indicate concurrence by the Federal Reserve Bank of St. Louis or the Federal Reserve System. 
to explain the remarkably slow recovery of consumer spending since the trough of the recession. These results support the implications of models in which upward redistribution slows the economy, as seen in the slow rebound of aggregate output and employment in the US. But a complete historical understanding of these events requires us to link redistribution with the dynamics of the household balance sheet, because household borrowing postponed the full brunt of inequality-induced demand drag for decades prior to the Great Recession.

The discussion to follow puts evidence from our earlier work into a broader context and extends it in a variety of ways to make the argument that rising income inequality is now a significant barrier to economic growth and full employment in the US economy. Because the US is an important engine of the global economic system, along with the fact that there are parallel phenomena operating in other mature economies, the perspective presented here is also relevant for much of the developed world outside of US borders.

\section{DEMAND AND GROWTH BEYOND THE SHORT RUN: THEORY AND RECENT EVIDENCE}

Our interpretation of recent macroeconomic trends in the US household sector follows from a macroeconomic perspective in which growth requires two dynamic structural processes that evolve separately, at least to an important extent. First is the supply side, the resources and technology that give the economy the potential to produce an expanding volume of goods and services. Rising supply is a necessary condition for growth, at least implicitly, in any macroeconomic theory, mainstream or otherwise. Where we part company with almost all mainstream growth theory is to assert that supply-side growth is not sufficient to realize rising standards of living, and at least an approximation to full employment, because the ability of business to sell its supply-determined potential output is not automatic. What we call the demand generation process is a second structural pillar of growth that has an independent impact on output and employment. A weak demand generation process can keep the economy below its potential output path indefinitely. ${ }^{1}$

The theoretical perspective that we employ differs from so-called 'New Keynesian' theory in which demand shocks affect output and employment in the short run only. Over horizons exceeding a few years, real effects of demand shocks in these models converge to zero, typically because of nominal adjustment or enlightened monetary policy. We are skeptical about the effectiveness of these channels. Theoretical and empirical research shows how disinflation and deflation can be destabilizing, especially in modern economies with substantial nominal debt contracts. ${ }^{2}$ We doubt that monetary policy can effectively eliminate demand constraints because of both the zero lower bound for nominal interest rates and the likelihood that attempts to stimulate persistently stagnant

1. There are undoubtedly many ways in which the dynamics of the supply side and demand side are linked. For example, a strong demand side leads to higher capacity utilization that stimulates capital formation and R\&D which both affect the supply side. Alternatively, technological innovation of a desirable consumer product could stimulate demand growth. Our main point here is that demand generation is independent of the supply side to a large enough extent that demand can constrain output and employment growth below a supply-determined growth path, which should not be interpreted as denying important linkages between supply and demand.

2. A summary of this research appears in Fazzari et al. (1998). See Palley (2008) for a more recent contribution. 
demand with low interest rates will create unsustainable borrowing trends that ultimately result in financial instability (see Summers 2014a; 2014b). For these reasons, the strength or weakness of the demand generation process can affect the path of the economy beyond the textbook 'short run' of mainstream macroeconomic models.

The long-run effects of demand generation on economic growth have been extensively discussed in heterodox macroeconomic research (see Setterfield 2010 and Lavoie 2014: ch. 6 for recent contributions and extensive references). But long-run growth paths are almost exclusively supply-driven in mainstream macroeconomics. Nonetheless, recent experience has begun to reveal cracks in the supply-side hegemony of mainstream growth models. In a 2013 address to the IMF, Laurence Summers resurrected the term 'secular stagnation' (originally coined by Alvin Hansen). Summers (2014a; 2014b) describes the US economy since the Great Recession as persistently below its potential due to insufficient demand. In our words, this perspective argues that demand generation constrains the economy beyond the short run. Similar ideas have been expressed by prominent economists such as Paul Krugman and Joseph Stiglitz.

We have come to call this theoretical perspective the intrinsic Keynesian model. We argue that Keynesian demand constraints in mature capitalism are not just temporary deviations from a supply-determined growth path but that Keynesian demand effects can limit output and employment by the very nature of the way that monetary economies operate. It is from this perspective that we explore the implication of rising inequality.

To connect inequality in the distribution of income across households to aggregate demand, we need to analyse the demand forthcoming from the household sector. For those familiar with the US National Income and Product Accounts (NIPA), this objective suggests that the relevant macroeconomic series is personal consumption expenditures (PCE). But on a deep dive into the definition of PCE we have found major deviations between PCE and actual household cash expenditure that motivates production and employment. PCE includes an extensive set of items that do not represent household cash expenditure. An important example is implicit rent that homeowners who occupy their houses are assumed to pay to themselves. Furthermore, PCE includes spending that does not come out of income as typically perceived by households. An example is spending on medical care paid for by third parties, usually the government or employer-provided health insurance. In addition, construction of new and renovation of existing owner-occupied homes, a critical source of demand arising from the household sector, is excluded from PCE and combined with business investment instead in the NIPA accounts. In Cynamon/Fazzari (2015b) we document these items, and many more, in detail for the entire household sector. We adjust the NIPA PCE measure to arrive at what we define as adjusted household demand that represents the actual cash spending under the control of the household sector. To the extent that rising household income inequality has macroeconomic effects through intrinsic Keynesian demand channels, it is best captured in the aggregate by this new variable. We also adjust household income, removing implicit receipts and items like third-party medical payments that households never perceive as disposable income.

Figure 1 presents a central motivating fact for the analysis in this article. It shows US real adjusted household demand from 2000 to 2013 . The dashed line is the peak-to-peak growth trend of adjusted household demand from 2000 to 2006 extended through 2013. As the figure shows, household demand conformed closely to the trend between 2000 and 2006, even during the recession year of 2001 and slow recovery of 2002 and 2003. But prior to the official beginning of the Great Recession in 2007, our adjusted household demand series drops well below the trend (3.1 percent). In 2008 and 2009 household demand collapses until it is 16.4 percent below the previous trend by 2009 . The US 


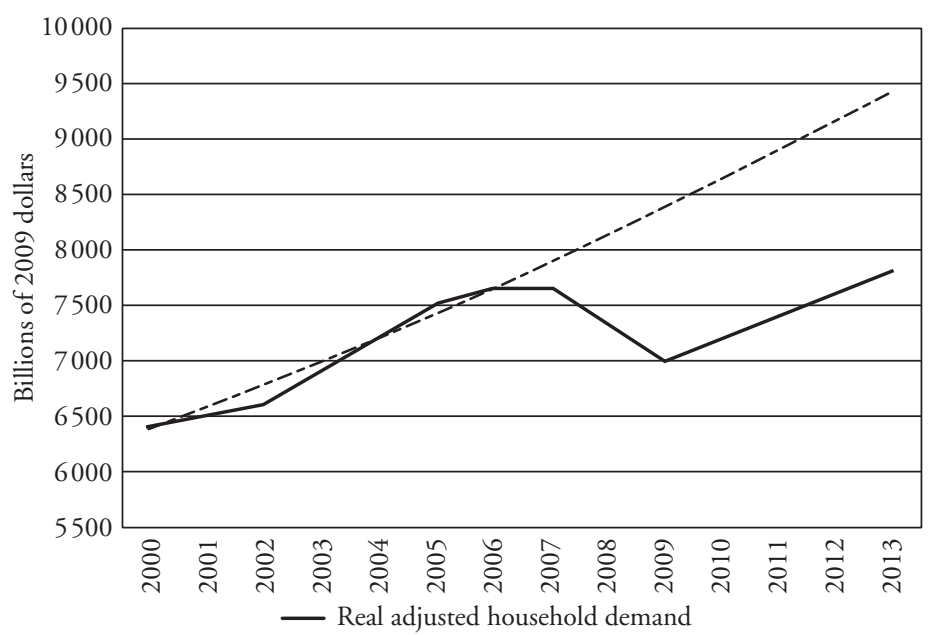

Figure 1 Real adjusted household demand and pre-recession trend

recovery begins in mid 2009 and this recovery is usually portrayed as strong in comparison to other developed countries. Yet our measure of household demand does not catch up with the trend. Indeed, by 2013 household demand is a bit further below the trend (17.5 percent) than it was at the trough of the recession. ${ }^{3}$

The gap between the trend in real adjusted household demand and its actual level from 2008 onward represents a huge drag on the US economy, and it is indeed the case that GDP also fell much below the pre-recession trend and remains there as of this writing in early 2015. Of course, a simple trend does not capture many structural features of the demand generation dynamics of the US household sector prior to the Great Recession. But it does summarize the household demand growth that was necessary after 2000 to restore the economy to at least an approximation of full employment by $2006 .{ }^{4}$

It is common to see arguments that US household demand was, at least in some senses, excessive and unsustainable prior to the Great Recession. We agree that financial conditions and balance sheet trends in the household sector were unsustainable (we make such arguments explicitly in Cynamon/Fazzari 2013; also see Palley 2002; Dutt 2006; Barba/ Pivetti 2009; Setterfield/Kim 2014), but we do not accept the view that the total volume of US household demand was excessive in 2006 and 2007. None of the typical signs of an overheated demand boom were evident in those years. Inflation was tame; interest rates were low; wage growth was slow, even stagnant, over most of the employed population.

3. Somewhat different conclusions follow if one uses the real NIPA PCE measure of the household sector as a proxy for household demand. Real NIPA PCE is just 0.8 percent below its 20002006 growth trend in 2007. In 2009 real PCE is 12.1 percent below trend and it recovers more quickly, to 8.6 percent below trend by 2013 .

4. The US civilian unemployment rate reached its lowest level in decades of 3.8 percent in April of 2000 before rising in the 2001 recession. It recovered to a minimum of 4.4 percent in early 2007. Therefore, while we agree with authors like Tcherneva (2012) that the US labor market faced significant barriers to full employment even before the Great Recession, labor market conditions in 2006 and early 2007 were nearly as good as they had been in many decades, at least statistically. 
The employment-population ratio was rising modestly by the middle 2000s, but it remained well below its early 2000 peak. There is no evidence that US demand was outstripping supply. We agree with Summers (2014b: 31), who writes that it 'would not be right to say either that growth was spectacular or that the economy was overheating' in the years prior to the Great Recession. Furthermore, Summers (ibid.: 31) clearly explains the distinction between household spending that was financed in an unsustainable way and a total volume of spending that was excessive: 'Imagine that US credit standards had been maintained, that housing had not turned into a bubble, and that fiscal and monetary policy had not been stimulative [between 2003 and 2007]. In all likelihood, output growth would have been manifestly inadequate because of an insufficiency of demand.' The US economy needed the trend growth of household demand it actually had from 2000 through 2006.

Aggregate evidence supports the view that insufficient demand held the US economy back well after the disastrous collapse of 2008 and 2009. When the severity of the Great Recession became broadly recognized, many forecasters predicted a quick rebound of the economy, citing research that deep recessions are typically followed by strong recoveries. But this was not the case. Annualized growth of real GDP from the trough of the Great Recession in the second quarter of 2009 through the fourth quarter of 2014 (22 quarters) was just 2.3 percent. Following the troughs of much milder recessions in the first quarter of 1991 and the third quarter of 2001, annualized growth for the next 22 quarters was substantially higher, 3.3 percent and 2.8 percent respectively. It took 77 months from the beginning of the recession in December 2007 for the number of jobs (payroll employment) to once again reach the pre-recession level, much longer than in any other postwar recession. The civilian employment-population ratio fell 5.2 percentage points during the recession (from its peak in December 2006 to a trough in June 2011) but recovered just 1.0 percentage point through December 2014. We connect this weak performance with a stagnant demand generation process. Why was demand growth so sluggish in this period? The main point of this article is that the answer to this question relies to an important extent on the rise of income inequality in previous decades, as we now discuss.

\section{RISING INCOME INEQUALITY AND THE US DEMAND GAP}

The dramatic rise of income inequality in the US is well known. In Cynamon/Fazzari (2015a, hereafter referred to as $\mathrm{C} / \mathrm{F}$ ) we focus on the income share of the top 5 percent of the personal income distribution, with income defined before taxes and including realized capital gains. According to the World Top Incomes Database, this share was remarkably stable between 1960 and 1984, fluctuating between 22 percent and 24 percent. It began to rise significantly in the early 1980s, reaching 39 percent by 2009 before receding a bit in the immediate aftermath of the Great Recession to 36 percent. $^{5}$

These historical trends could create demand drag for at least two reasons. First, it seems likely that propensities to consume out of after-tax income are lower for high-income households. If more of the economy's income flows into the hands of the affluent, then the average propensity to consume for the economy as a whole will fall. Second, marginal tax rates are higher for higher income groups.

Despite these fairly clear implications of rising inequality for demand generation, a casual look at empirical evidence suggests a problem with the timing of this basic story. When income inequality in the US began to rise around 1980, the ratio of aggregate

5. High incomes tend to be more volatile over the business cycle than the rest of the income distribution, especially if the income measure includes realized capital gains. 
household demand to disposable income did not decline. Figure 2 shows the ratio of our adjusted cash flow measures of household demand to disposable income. This ratio was volatile in the 1980s and early 1990s with no clear trend; it stabilized in the late 1990s and early 2000s at a rather high level by historical standards; and it then spiked upward in the last phase of the recent housing boom from 2004 through 2006. What this demand ratio did not do was decline when income inequality began to rise in the early 1980s (the decline evident from 1980 to 1982 was clearly temporary in the deep recession that bottomed out in the summer of 1982). It may seem that rising income inequality did not constrain household demand at all if demand as a share of cash income did not decline for decades after income inequality began to rise. ${ }^{6}$

In $\mathrm{C} / \mathrm{F}$ we propose that this simple interpretation is misleading because it ignores important financial dynamics of the household sector, dynamics that would ultimately prove

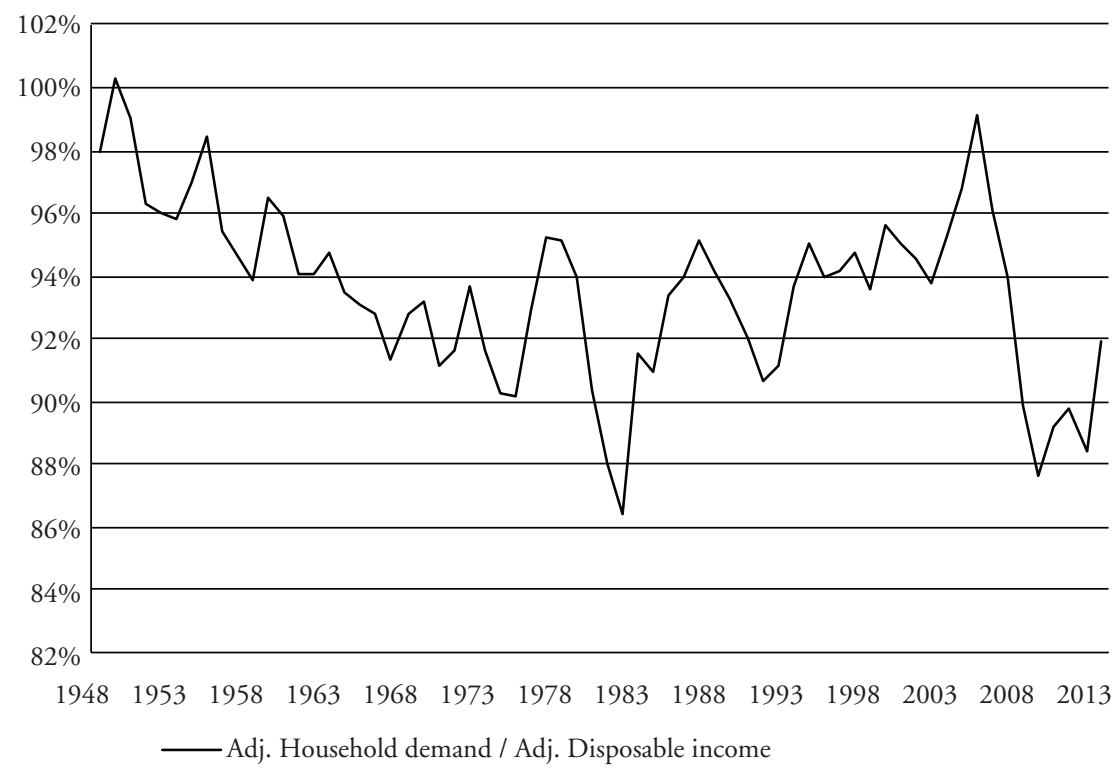

Figure 2 Household demand to disposable income

6. A referee points out that the absence of an obvious trend in the ratio from Figure 2 in the decades prior to the Great Recession, based on our adjusted variables, contrasts with the upward trend in the ratio of NIPA PCE to NIPA disposable personal income. The greater volatility of our adjusted series, due largely to the integration of residential construction with consumption spending, makes the ability to discern trends more difficult. Nonetheless, most likely there was some increase in the adjusted ratio that parallels the standard measure. For example, the ratio of NIPA PCE to disposable income rises by 7.5 percentage points from an approximate minimum averaged over 1970 to 1973 to an approximate pre-crisis maximum averaged over 2003 to 2006. The same statistic for the adjusted ratio in Figure 2 rises 4.8 percentage points. For our purposes here, the main point is that there is no systematic decline in the ratio plotted in Figure 2 during the period of rising income inequality from about 1980 to the Great Recession. In addition, we note that adjusted household outlays, which include interest payments, relative to adjusted disposable income does have a strong upward trend from the mid 1970s to the eve of the Great Recession. See Cynamon/Fazzari (2015b) for further discussion. 
unsustainable and trigger the Great Recession. We argue that the demand drag from rising income inequality was postponed in the US economy by massive household borrowing. The rise in the household debt-disposable income ratio is well known. Figure 3 shows that ratio using the new adjusted cash flow income concept and measure of household debt developed in Cynamon/Fazzari (2015b). ${ }^{7}$ After a period of stability from the early 1960s through the 1970s, the debt-income ratio clearly begins to rise around 1980, at roughly the same time that income inequality begins to increase.

What kind of evidence can be used to assess the view that rising income inequality played an important role in the run-up of debt prior to Great Recession? In C/F we show that rising inequality occurred, in part, as the result of a drop in real income growth for the bottom 95 percent of the income distribution. We show that for this group to keep its balance sheet stable under these circumstances it would have had to lower its ratio of spending to income. Furthermore, real interest rates rose substantially around the same time as income inequality began to increase. As emphasized by Mason/Jayadev (2014), this fact also would have required a further reduction in the spending-income ratio to maintain a stable debt-income ratio. Consistent with the data in Figure 2, we present original evidence in $\mathrm{C} / \mathrm{F}$ to show that the demand-income ratio of the bottom 95 percent did not decline; if anything, it increased modestly. The predictable result of slower income growth, higher real interest rates, and a ratio of spending to income that did not decline was a dramatic increase in the debt-income ratio. While that outcome is evident in the aggregate data in Figure 3, C/F further link the leveraging of the household sector to rising inequality by showing that the rise in debt-income was much more severe for the bottom 95 percent of the income distribution than for the top 5 percent. $^{8}$

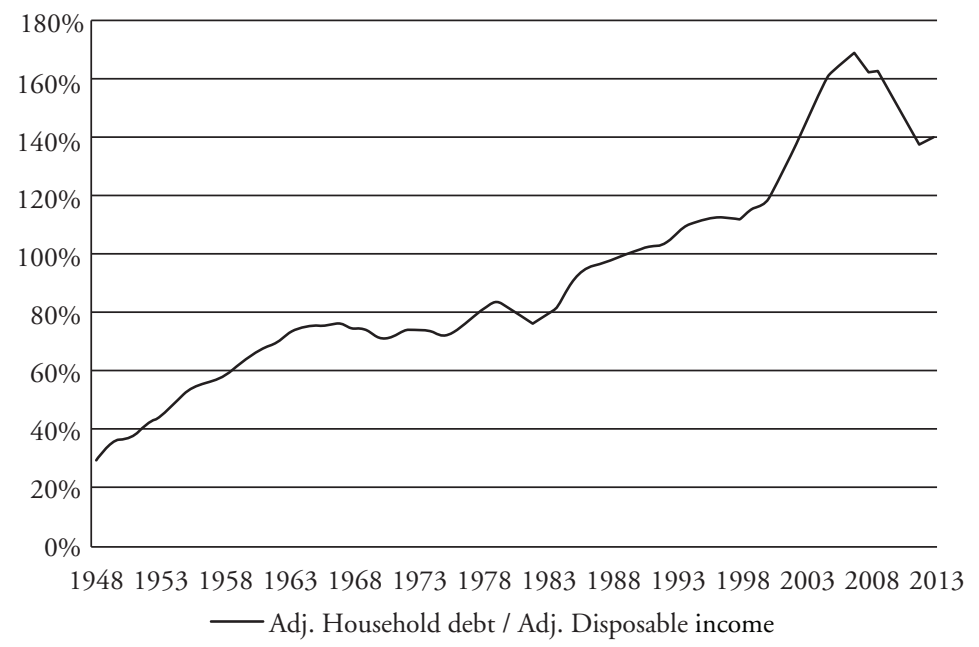

Figure 3 Household debt to disposable income

7. We adjust the household sector measure of debt from the Flow of Funds Accounts to exclude liabilities of non-profit institutions.

8. The empirical evidence in $\mathrm{C} / \mathrm{F}$ is based on NIPA measures of personal consumption expenditure and disposable income rather than the adjusted cash flow measures highlighted in this article. This is because the information necessary to disaggregate the adjusted measures is not available. 
Perhaps the most important result from the disaggregated data in $\mathrm{C} / \mathrm{F}$ is the difference between what happens to consumption spending across the two income groups that we study once the Great Recession hits. The mainstream life-cycle model of consumer behavior predicts that households will try to smooth consumption through a recession, even as income declines. If this model is correct, then the consumption-income ratio should rise in recessions. Indeed, this is what we find in $\mathrm{C} / \mathrm{F}$ for the top 5 percent group in every recession since the beginning of our disaggregated data series in 1989. The effect is particularly strong in the sharp contraction of income during the Great Recession. But things are quite different for the bottom 95 percent. The consumption-income ratio for this group declines substantially in the Great Recession, from a 2005 peak to a trough in 2010. This outcome is consistent with our interpretation of the way that rising inequality and household borrowing has interacted to affect US macroeconomic dynamics in recent years. From the early 1980s until the eve of the Great Recession, the bottom 95 percent maintained high consumption despite their stagnating incomes, postponing demand drag from rising inequality. The result was an ultimately unsustainable, but persistent, increase in household leverage and financial fragility. When the financial crisis of the Great Recession cuts off the access to new debt for much of the bottom 95 percent, their consumption spending is forced back onto a lower path. But even though this path is more consistent with the financial circumstances of the bottom 95 percent, it no longer generates the demand necessary to keep economy near full employment.

The evidence discussed in this section makes a strong case that the consumption gap evident in Figure 1 is to a large extent the result of declining spending by the group of households that received a lower share of income as inequality increased. The demand drag from rising income inequality was deferred for a number of years by massive borrowing by the same group, but that process came to an end with the financial crisis. The consequent demand gap from the bottom 95 percent has not been offset by the spending from the top 5 percent, which should not be surprising. Our evidence implies that it was the bottom 95 percent that were spending unsustainably prior to the Great Recession. There is no reason to think that the top 5 percent were under-consuming in any sense before 2007. When the debt and spending dynamics of the bottom 95 percent hit the wall, therefore, there was an insufficient boost in demand from the affluent to offset the shortfall in bottom 95 percent consumption.

\section{INEQUALITY AND DEMAND IN THE AFTERMATH OF THE GREAT RECESSION}

The US recovery from the Great Recession has been disappointing, an outcome that we attribute in large part to the impact of rising income inequality on household demand. Figure 4 provides some support for this interpretation. It shows the profile of real adjusted household demand following each US recession since 1974. Real demand is indexed to 100 in the year preceding the recession and the profiles extend for 7 years. ${ }^{9}$ In the four business cycles prior to the Great Recession, real household demand recovered after 7 years to a level that averaged 18 percent higher than the pre-recession peak. But 7 years after the peak of the Great Recession, real household demand is just 2 percent above its 2006 peak. The household sector is not even close to playing its typical role in generating demand in the aftermath of the Great Recession.

9. We choose 7 years because our adjusted demand data end in 2013, 7 years from the 2006 peak prior to the Great Recession. 


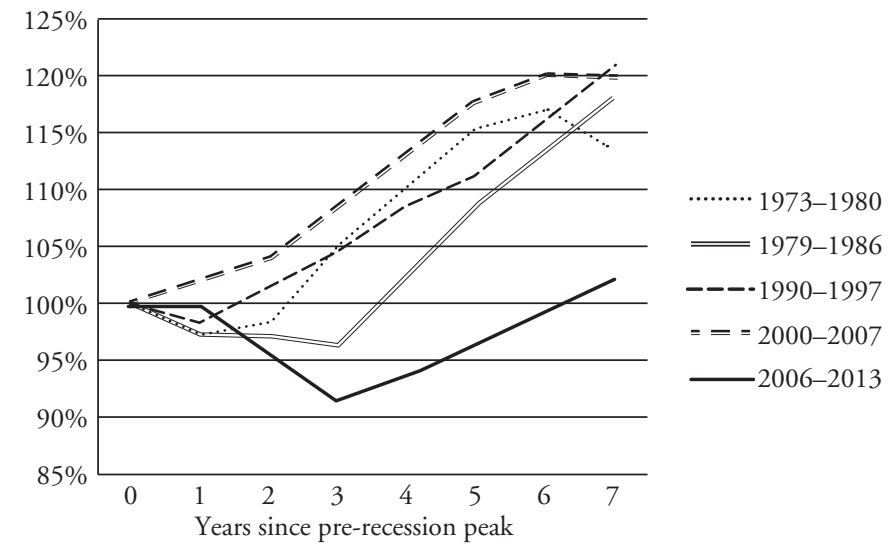

Figure 4 Real household demand profiles from peak prior to recessions

Let us consider the quantitative effect of rising income inequality as a possible explanation of this recent history. We estimate a simple counterfactual for what household demand might now look like with income shares of the 5 percent and 95 percent groups that are representative of the shares that prevailed before the rise in inequality. We modify the aggregate demand-driven growth model from Fazzari et al. (2013) to account for distributional shifts, an approach consistent with the intrinsic Keynesian theoretical context. According to that model, the steady-state growth path at any point in time is given by autonomous demand multiplied by a term that is a dynamic extension of the simple Keynesian multiplier (see Fazzari et al. 2013: equ. 3.7). For the purposes here, this multiplier can be approximated by the inverse of one minus the household demand-income ratio. ${ }^{10}$ Suppose that there are two income groups, $H$ and $L$. Denote the marginal propensity to consume out of after-tax income for group $j$ as $\lambda_{j}$ and the marginal tax rate as $\tau_{j}$. Let $\lambda_{H}$ be the share of income earned by the high-income group $H$. The multiplier is:

$$
M=\frac{1}{1-\lambda_{H} \alpha_{H}\left(1-\tau_{H}\right)-\left(1-\lambda_{H}\right) \alpha_{L}\left(1-\tau_{L}\right)}
$$

We can approximate the proportionate effect of income distribution on the level of output at any point in time along the growth path by calibrating this formula and changing the distribution parameter $\lambda_{H}$.

The average, and approximately stable, pre-tax income share of the top 5 percent from the World Top Incomes database (including realized capital gains) was 22.8 percent from 1960 through 1984 which is our initial value for $\lambda_{H}$. This share rose to 38.7 percent in

10. This approximation ignores investment accelerator terms that would raise the multiplier somewhat. But it also ignores endogenous imports that would reduce the multiplier. The net effect of these two factors is likely small compared with the household demand terms analysed in the text. In the Fazzari et al. (2013) model, the actual path of output need not converge to a steady-state growth path in the model, but in this unstable case the steady-state path approximates the bottom range of cyclical growth. 
Table 1 Calibrated effects of change in distribution on the multiplier

\begin{tabular}{lccc}
\hline $\begin{array}{l}\text { Source for MPC } \\
\text { parameters }\end{array}$ & $\begin{array}{c}\text { Bottom 95\% } \\
\text { MPC, } \alpha_{L}\end{array}$ & $\begin{array}{c}\text { Top 5\% } \\
\text { MPC, } \alpha_{H}\end{array}$ & $\begin{array}{c}\text { Impact of change in shares } \\
\left(\Delta \lambda_{H}\right)\end{array}$ \\
\hline Johnson et al. (2006) & 0.40 & 0.20 & $-3.7 \%$ \\
C/F & 0.92 & 0.82 & $-9.5 \%$ \\
Bakker/Felman (2014) & 0.95 & 0.65 & $-13.6 \%$ \\
\hline
\end{tabular}

Note: These results assume marginal tax rates for the bottom $95 \%\left(\tau_{L}\right)$ and top $5 \%\left(\tau_{H}\right)$ of 0.20 and 0.40 respectively. The change in the pre-tax income share of the top $5 \%\left(\Delta \lambda_{H}\right)$ is $22.8 \%$ to $36.6 \%$.

2009 before dropping modestly in the years immediately following the Great Recession. We use the average top 5 percent share from 2008 through 2012 of 36.6 percent as the final value for $\lambda_{H}$. The marginal tax rate for the top 5 percent $\left(\tau_{H}\right)$, including federal and state income taxes and payroll taxes, is assumed to be 40 percent. We assume that the bottom 95 percent tax rate $\left(\tau_{L}\right)$ is 20 percent. Consider three different settings for the marginal propensities to consume. First, let $\alpha_{L}=0.4$ and $\alpha_{H}=0.2$. These settings represent the effect of temporary income shocks on consumption. The empirical values are consistent with the aggregate evidence presented by Johnson et al. (2006) for the effect of the 2001 tax rebate on consumption (with the bottom 95 percent set at the top of the estimated MPC range and the top 5 percent set at the bottom). With these values, the multiplier $M$ falls 3.7 percent as the distribution parameter $\lambda_{H}$ goes from 22.8 percent to 36.6 percent (see Table 1). This decline, which corresponds to a 4 percent reduction in GDP according to the model, is not trivial. But this calibration of the consumption parameters probably understates the output effects for this kind of counterfactual analysis. That is because the relevant experiment is not a temporary shock to income. Rather, it is a long-run change in the income growth paths of the two groups. In this case, the appropriate consumption propensities are much higher. The average share of after-tax income consumed by the bottom 95 percent and the top 5 percent from the data we develop in $\mathrm{Cl}$ F gives $\alpha_{L}=0.92$ and $\alpha_{H}=0.82$. This difference between the two groups is smaller than implied by the temporary propensities used for our first case, but the non-linear interaction of these parameters with the tax rates and the distribution parameter result in a much bigger effect on the multiplier, a decline of 9.5 percent. But the differential consumption rates from $\mathrm{C} / \mathrm{F}$ imply a lower difference between the groups than other estimates. For example, in a recent paper, Bakker/Felman (2014) estimate marginal propensities to consume of $\alpha_{L}=0.95$ and $\alpha_{H}=0.65$, and others find even larger differences. ${ }^{11}$ With the Bakker/ Felman estimates, the multiplier declines by 13.6 percent.

Let us put these results into perspective. The distributional shift was not a sudden shock, but a slow process that took place over decades. And any effect on consumption of this shift did not necessarily occur at the same time as the change in distribution: as discussed previously the demand drag from rising inequality was postponed by household sector borrowing. But now that the borrowing binge is over, we argue that the distributional shift is constraining the growth path of household demand. The numerical results show that current output could easily be 10 percent or more below the demand-led growth path that could prevail if the distribution of income between the bottom 95 percent and top 5 percent

11. Bakker/Felman (2014) estimate these parameters for the bottom 90 percent and top 10 percent respectively. Differences in the consumption parameters between high and low income groups could be even larger. See Dynan et al. (2004), for example. 
were at levels consistent with the roughly stable income shares of the 1960s and 1970s. These issues should be studied with a more complete dynamic model that accounts for the interaction of changing income distribution, the run-up of household borrowing, and the end of the borrowing boom. But the first steps presented here show that it is entirely plausible that the magnitude of rising inequality that actually occurred in the US over recent decades is large enough to explain a large shortfall of household demand, like the one apparent in Figure 1.

\section{DEMAND GENERATION AND ECONOMIC DEMOCRACY}

We present the case in this article that the rise of inequality in the personal distribution of income has indeed become a barrier to growth and employment for the US economy. The effect of inequality on demand generation was postponed by massive consumer borrowing for an extended period prior to the Great Recession, but it now is holding back output and employment. The core of our argument is straightforward:

1. The US economy after the Great Recession has recovered slowly because of inadequate demand generation.

2. Demand generation would be stronger if lower income groups received a higher share of total income.

3. The magnitude of this effect could be big enough to explain an output gap of 10 percent, if not higher.

Figure 5 offers some additional perspective to this argument. It shows an index of real consumption growth for the bottom 95 percent and top 5 percent of the income distribution with data drawn from $\mathrm{C} / \mathrm{F} .^{12}$

Figure 5 illustrates several features of the analysis presented in this article. The overall impact of inequality is striking. Real consumption of the top 5 percent grew 77 percentage points more than consumption for the bottom 95 percent from 1989 to 2012. That is, real consumption growth for the top 5 percent was more than double that of everyone else. Also, notice that while the cumulative growth of the bottom 95 percent fell behind that of the top 5 percent after 1995, the consumption of the bottom group did grow through 2007, despite stagnant incomes for the same group. As discussed previously, the bottom 95 percent greatly increased their debt-income ratio through 2007 (much more than the top 5 percent). But when the expanding balance sheets of the bottom 95 percent hit the wall of the Great Recession and suddenly began to contract, the real consumption growth of this group came to a halt. The consumption of the top 5 percent was also clearly affected by the Great Recession, but the effect was temporary.

The stagnation of bottom 95 percent consumption growth over the past few years evident in Figure 5 demonstrates the demand drag we attribute, in large part, to rising income inequality that has finally manifested itself in demand generation after the Great Recession. No doubt, the spending of the affluent has helped to power demand generation during the past few years, and that is an important reason why there is some recovery in the US economy. But the stagnation in the bottom 95 percent, which still

12. Again we note that the $\mathrm{C} / \mathrm{F}$ data are a decomposition of NIPA PCE rather than the adjusted household demand series we discuss elsewhere in this article, because we do not have the information necessary to disaggregate adjusted demand. 


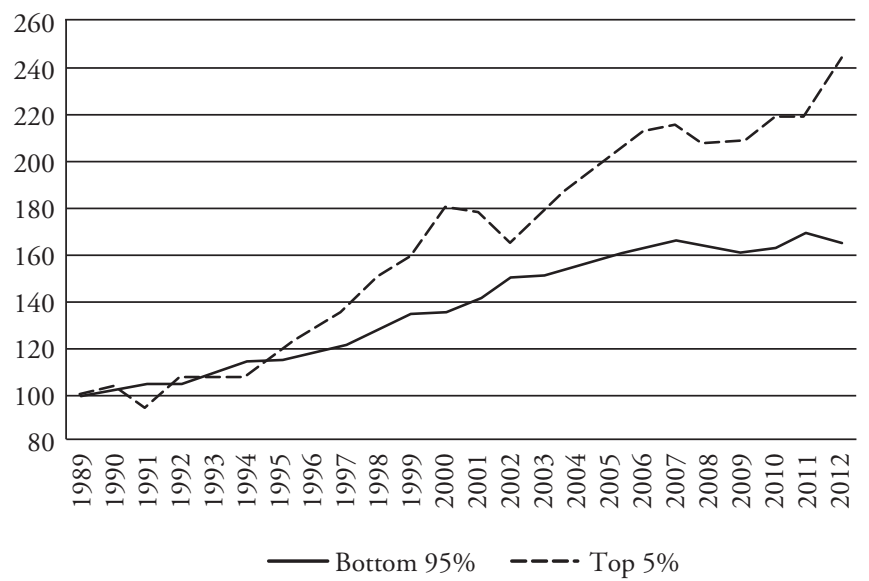

Figure 5 Real consumption indices by income groups $(1989=100)$

accounted for over 70 percent of total PCE as of 2012, has opened a large gap in demand generation that has not been filled.

Should the demand generated by the affluent continue its strong upward trend (annualized real growth of 4.9 percent from 2009 through 2012), it will become more and more important to the health of the economy, a phenomenon already recognized in the popular press, if not academic analysis. ${ }^{13}$ Perhaps robust spending of the rich as the engine of demand generation represents a new era for the US, and it may have the potential to close the kind of demand gap shown in Figure 1 over the coming years. But this trend will likely exacerbate the social tension of rising economic inequality that is becoming more prominent in US political discourse. ${ }^{14}$ The structure of demand generation has become decidedly less democratic in recent years. The price paid in terms of a sluggish recovery from a historic recession is already high. This price will likely rise unless income inequality stabilizes or, better yet, reverses.

\section{REFERENCES}

Bakker, B.B., Felman, J. (2014): The rich and the Great Recession, IMF Working Paper 14/225. Barba, A., Pivetti, M. (2009): Rising household debt: its causes and macroeconomic implications: a long period analysis, in: Cambridge Journal of Economics, 33(1), 113-137.

Cynamon, B.Z., Fazzari, S.M. (2013): Household spending and debt: sources of past growth: seeds of recent collapse, in: Cynamon, B.Z., Fazzari, S.M., Setterfield, M. (eds), After the Great Recession: The Struggle for Economic Recovery and Growth, New York: Cambridge University Press, 127-157.

13. For example, see 'The middle class is steadily eroding. Just ask the business world,' New York Times, 3 February 2014, p. A1 and 'How a two-tier economy is reshaping the U.S. marketplace,' Wall Street Journal, 29 January 2015, p. A1.

14. Even younger politicians in the Republican Party are now talking about addressing economic inequality, a new phenomenon among a political group that until recently often labeled any discussion of inequality as 'class warfare.' See Thomas Edsall, 'The Republican discovery of the poor,' New York Times, 11 February 2005. 
Cynamon, B.Z., Fazzari, S.M. (2015a): Inequality, the Great Recession, and slow recovery, in: Cambridge Journal of Economics, doi: 10.1093/cje/bev016.

Cynamon, B.Z., Fazzari, S.M. (2015b): Household income, demand, and saving: deriving macro data with micro data concepts, in: Review of Income and Wealth, doi: 10.1111/roiw.12206.

Dutt, A.K. (2006): Maturity, stagnation, and debt: a Steindlian approach, in: Metroeconomica, 57, 339-364.

Dynan, K., Skinner, J., Zeldes, S.P. (2004): Do the rich save more?, in: Journal of Political Economy, 112(2), 397-444.

Fazzari, S.M., Ferri, P., Greenberg, E. (1998): Aggregate demand and firm behavior: a new perspective on Keynesian microfoundations, in: Journal of Post Keynesian Economics, 20(4), 527-558.

Fazzari, S.M., Ferri, P., Greenberg, E., Variato, A. (2013): Aggregate demand, instability, and growth, in: Review of Keynesian Economics, 1(1), 1-21.

Hein, E. (2014): Distribution and Growth after Keynes, Cheltenham, UK and Northampton, MA: Edward Elgar.

Johnson, D.S., Parker, J.A., Souleles, N.S. (2006): Household expenditure and the income tax rebates of 2001, in: American Economic Review, 96(5), 1589-1610.

Lavoie, M. (2014): Post-Keynesian Economics: New Foundations, Cheltenham, UK and Northampton, MA: Edward Elgar.

Mason, J.W., Jayadev, A. (2014): 'Fisher dynamics' in US household debt, 1929-2011, in: American Economic Journal: Macroeconomics, 6(3), 214-234.

Palley, T.I. (2002): Economic contradictions coming home to roost? Does the US economy face a long-term aggregate demand generation problem?, in: Journal of Post Keynesian Economics, 25, 9-32.

Palley, T.I. (2008): Keynesian models of deflation and depression revisited, in: Journal of Economic Behavior and Organization, 68(1), 167-177.

Setterfield, M. (ed.) (2010): Handbook of Alternative Theories of Economic Growth, Cheltenham, UK and Northampton, MA: Edward Elgar.

Setterfield, M., Kim, Y.K. (2014): Debt Servicing, Aggregate Consumption, and Growth, unpublished manuscript, available at SSRN: http://ssrn.com/abstract=2364769.

Summers, L.H. (2014a): US economic prospects: secular stagnation, hysteresis, and the zero lower bound, in: Business Economics, 49(2), 65-73.

Summers, L.H. (2014b): Reflections on the 'New Secular Stagnation Hypothesis,' in: Teulings, C., Baldwin, R. (eds), Secular Stagnation: Facts, Causes and Cures, VoxEU.org eBook, ch. 1, 27-40, URL: http://www.voxeu.org/sites/default/files/Vox_secular_stagnation.pdf.

Tcherneva, P.R. (2012): The role of fiscal policy: lessons from stabilization efforts in the United States during the Great Recession, in: International Journal of Political Economy, 41(2), 5-26. 